\title{
Bridging the Soft-skills Deficit Gap Among Secondary Students in the UAE
}

\author{
Ms.Fadia Moosa Rasheed \\ Associate Professor, Emirates College for Management and Information Technology \\ United Arab Emirates \\ Prof. Nabeel A. Jurdi Ph.D. \\ President, Emirates College for Management and Information Technology \\ United Arab Emirates
}

\begin{abstract}
Educators are increasingly aware of the pivotal role that soft skills play in making sure students are adequately prepared to initiate collegiate education. Soft skills will be increasingly vital ingredient for success in postsecondary education and are very important for all students that need to develop their potential while in school. Soft skills are a valuable component and is a vital factor impacting the chances of student success in collegiate education. This indicates the importance and necessity of acquiring soft skills for the students while studying at schools. In this paper, five areas of soft skills namely communication skills, decision making and problem-solving skills, time management skills, teamwork and interpersonal skills , cultural competency skills are explored in an effort to find out the Soft-skills gap among secondary students in UAE . Though there are many other types of skills, the skills mentioned do provide a glimpse of the types of skills required for postsecondary success. The identified soft-skills gap need to be addressed rigorously to put the students in the higher trajectory for post-secondary success
\end{abstract}

Keywords: Soft skills; Gap Analysis, secondary education; postsecondary success

DOI: $10.7176 / \mathrm{JLPG} / 89-05$

Publication date:September $30^{\text {th }} 2019$

\section{Introductions}

Soft skills are important to enhance the level of students' success as well as help them to succeed in college level as well as social and personal life. The soft-skill acquisition provides confidence among the students through some established strategies for molding better academic standing towards personal success that will eventually develop skills in staying positive and motivated.

By, soft skills we mean personal attributes that will enhance students interactions and school performance such as creative; taking initiatives, communication skills, analytical thinking, team work, creativity, imaginative and resourceful('thinking outside the box'); ability to bring unique perspectives, and being expressive rather than being docile and so on. The assumption held in this study is that students will perform not up to expected level in university without basic soft-skills required to cope with and this deficit will lead to under-performance towards future development

Soft skills are known in different ways. (Allvin, 2016) refers to soft skills as mind-set or habits of mind or 21 st century learning skills. Soffel (2016) of the World Economic Forum refined into three categories: foundational literacies, competencies and character qualities. Duckworth (2016) calls it grit. Claxton, Costa and Kallick (2016) identified this as thinking and learning dispositions. Rao (2012) in his article explained soft skills as "polite and pleasing ways of presenting to others and are mostly related to personality, attitude and behavior". He further refined soft skills as a collection of skills and abilities relevant to communication, managing time, problem solving, negotiating, writing, listening, reading and decision-making. Diakiw (2016) opined that softs skills include the ability to complete a task, self-regulation, self-awareness, developing and maintaining positive relationships and healthy.

The UAE Knowledge agenda 2021 aims to equip students with high-order thinking skills in creativity, analysis, problem solving and developing information into knowledge capital to be distributed and used again(World bank,2012). We agree with the previous studies (Claxton,2006) that not all students are adept to resources that contribute to skills needed for successful completion of university education but can be a subject of gradual and systematic cultivation.

\section{Research Objectives}

The purpose of this study is to understand the factors that inhibit students from second cycle institutions in the UAE especially in Dubai from acquiring soft-skills in readiness for university learning. the UAE

Primary objective is to identify the soft-skill acquisition deficit among secondary school leaving students in 
Secondary objective is to understand the factors that hinder secondary students' ability to acquire soft skills in readiness for university education.

\section{3..Methodology}

Considering the large number of public and private schools in the UAE, , questionnaire covering 20 questions under 5 major parameters were administered through random sampling to collect the response.

Primary data were collected from the secondary school leaving students. Secondary data are collected from previous related studies, review papers, Journals .

\section{Data analysis and interpretations}

We analyze Soft skills that has five major components Each component will help students develop a particular set of skills. The five components are: communication skills, problem-solving and decision making skills, time management skills, teamwork and interpersonal skills , cultural competency skills which will provide important insights into surviving and succeeding in a collegiate environment; The soft skill indicators are :

COMMUNICATION SKILLS:

- $\quad$ Communicate accurately and concisely

- $\quad$ Listen effectively

- $\quad$ Effective oral communication

- $\quad$ Effective written communication

PROBLEM-SOLVING AND DECISION MAKING SKILLS

- $\quad$ Think outside the box

- Be Creative

- Take effective and appropriate decisions

- Take initiative

TIME MANAGEMENT SKILLS:

- $\quad$ Effective personal time management

- $\quad$ Sense of urgency to complete tasks

- Work well under pressure

- $\quad$ Punctual and meets deadlines

TEAMWORK AND INTERPERSONAL SKILLS

- $\quad$ Productive as a team member

- $\quad$ Share ideas to multiple audiences

- $\quad$ Work with multiple approaches

- Consistently demonstrates cooperation to complete a task

CULTURAL COMPETENCY SKILLS

- $\quad$ Recognize when to lead and when to follow

- $\quad$ Respect and acknowledge contributions from others

- $\quad$ Effectively exchange ideas and information with others

- $\quad$ Effectively works with people of diverse backgrounds

The data analysis and inference for each indicator is described below: 


\subsection{Communication skills:}

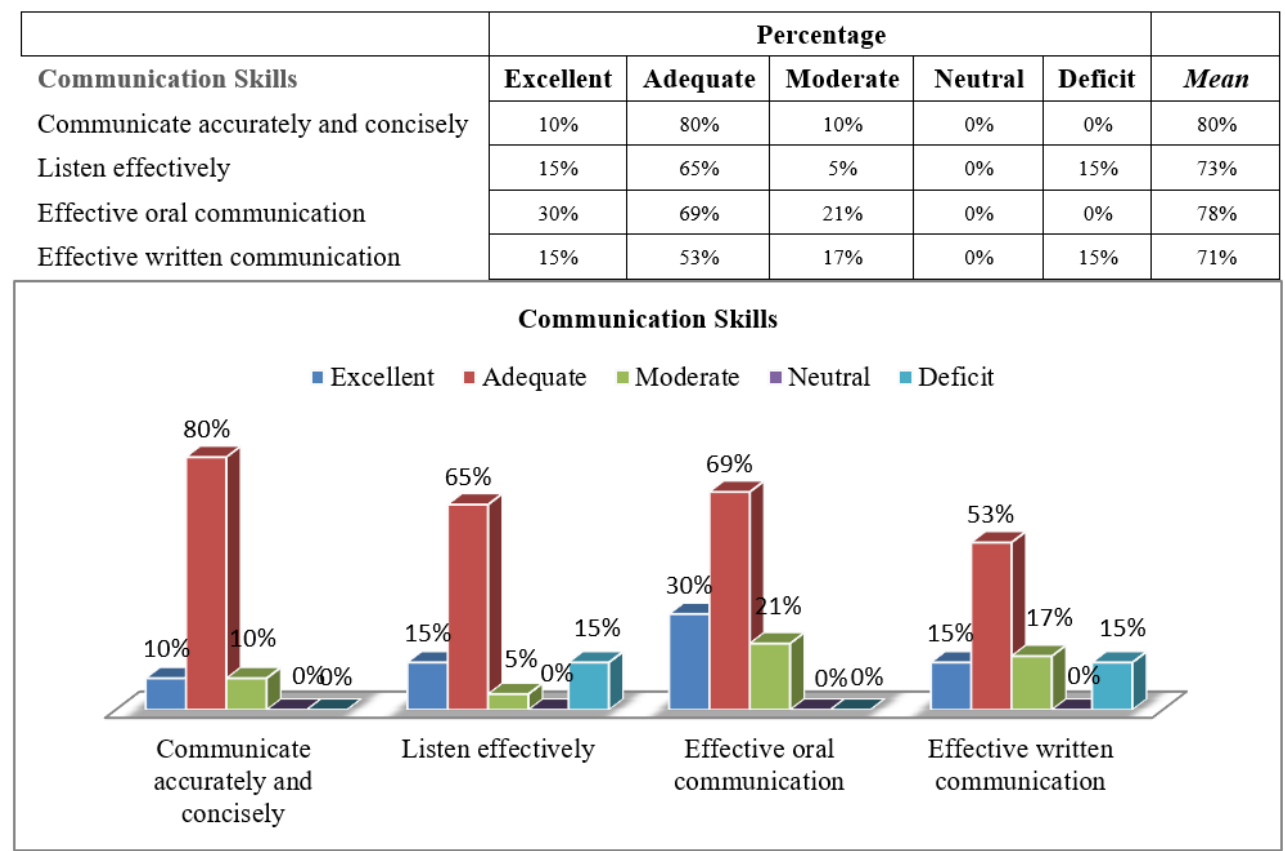

Inference: Overall the respondents are doing well in terms communication skill indicator "Communicate accurately and concisely" and "Effective oral communication"; but they are slightly sort of expectation in term of the other indicators like "Listen effectively" and "Effective written communication"

\subsection{Problem-Solving And Decision Making Skills:}

Inference: Overall the respondents are moderate and are sort of expectation in term of problem-solving and decision making skills indicators like "Think outside the box", "Be Creative", "Take effective and appropriate decisions ", "Take initiative"

\subsection{Time Management Skills:}

Time Management skills Effective personal time management Sense of urgency to complete tasks Work well under pressure Punctual and meets deadlines

\begin{tabular}{|c|c|c|c|c|c|}
\hline \multicolumn{5}{|c|}{ Percentage } & \\
\hline Excellent & Adequate & Moderate & Neutral & Deficit & Mean \\
\hline $20 \%$ & $70 \%$ & $10 \%$ & $0 \%$ & $0 \%$ & $82 \%$ \\
\hline $10 \%$ & $15 \%$ & $55 \%$ & $0 \%$ & $20 \%$ & $59 \%$ \\
\hline $26 \%$ & $15 \%$ & $62 \%$ & $0 \%$ & $18 \%$ & $58 \%$ \\
\hline $10 \%$ & $80 \%$ & $10 \%$ & $0 \%$ & $0 \%$ & $80 \%$ \\
\hline
\end{tabular}

Time Management Skills Excellent $\|$ Adequate $\|$ Moderate $\|$ Neutral $\|$ Deficit

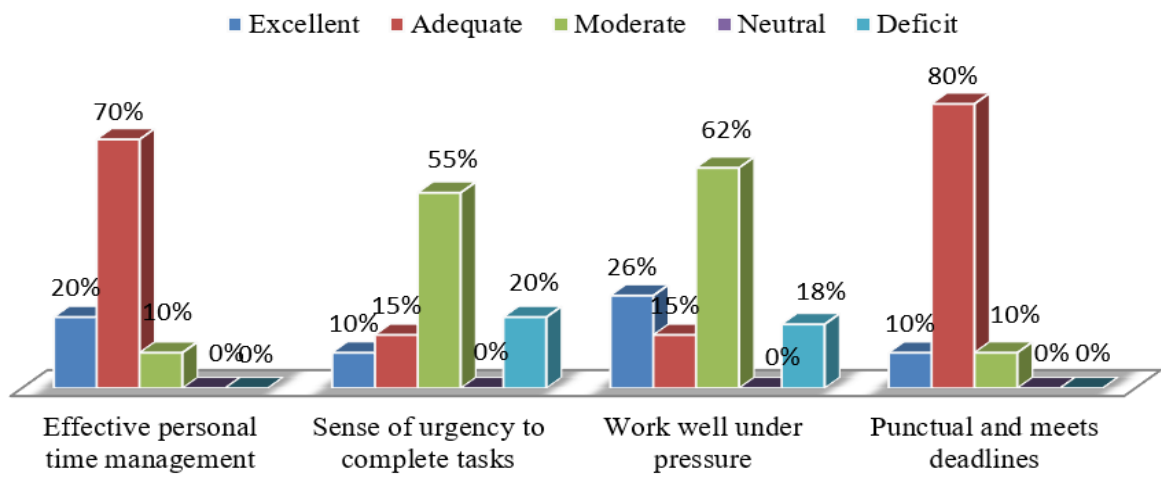

Inference: Overall the respondents are doing well in terms time management skills like "Effective personal time management", "Punctual and meets deadlines" and are sort of expectation in term of" Sense of urgency to complete tasks" and "Work well under pressure" 


\subsection{Teamwork And Interpersonal Skills:}

Teamwork and Interpersonal skills

Productive as a team member

Share ideas to multiple audiences

Work with multiple approaches

Consistently demonstrates cooperation to complete a task

\begin{tabular}{|c|c|c|c|c|c|}
\hline \multicolumn{5}{|c|}{ Percentage } & \\
\hline Excellent & Adequate & Moderate & Neutral & Deficit & Mean \\
\hline $25 \%$ & $55 \%$ & $20 \%$ & $0 \%$ & $0 \%$ & $81 \%$ \\
\hline $20 \%$ & $65 \%$ & $15 \%$ & $0 \%$ & $0 \%$ & $81 \%$ \\
\hline $20 \%$ & $20 \%$ & $45 \%$ & $0 \%$ & $25 \%$ & $58 \%$ \\
\hline $5 \%$ & $15 \%$ & $55 \%$ & $25 \%$ & $0 \%$ & $60 \%$ \\
\hline
\end{tabular}

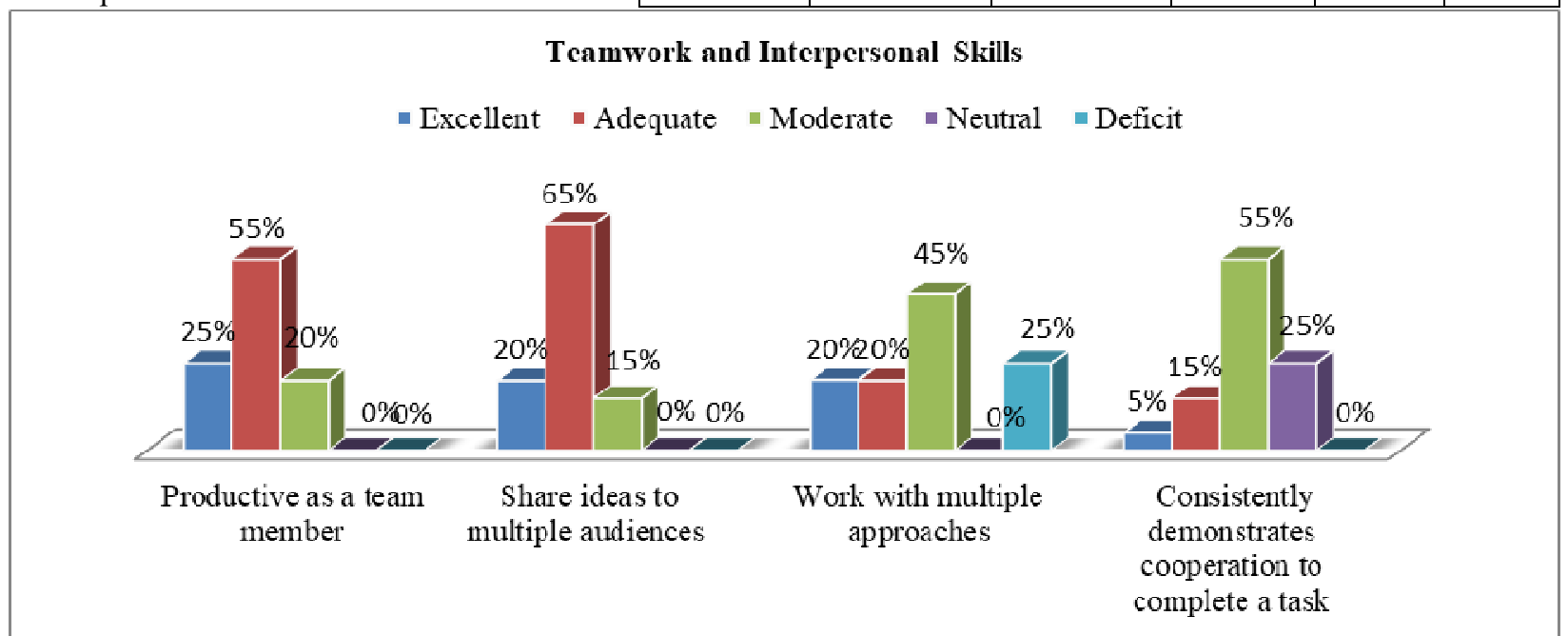

Inference: Overall the respondents are doing well in terms of indicators like "Productive as a team member" and "Share ideas to multiple audiences" ; but they are slightly sort of expectation in terms of indicators like "Work with multiple approaches", and "Consistently demonstrates cooperation to complete a task"

\subsection{Cultural Competency Skills}

\begin{tabular}{|c|c|c|c|c|c|c|}
\hline \multirow{6}{*}{$\begin{array}{l}\text { Cultural competency skills } \\
\text { Recognize when to lead and when to follow } \\
\text { Respect and acknowledge contributions } \\
\text { from others } \\
\text { Effectively exchange ideas and information } \\
\text { with others } \\
\text { Effectively works with people of diverse }\end{array}$} & \multicolumn{5}{|c|}{ Percentage } & \multirow[b]{2}{*}{ Mean } \\
\hline & Excellent & Adequate & Moderate & Neutral & Deficit & \\
\hline & $5 \%$ & $20 \%$ & $55 \%$ & $0 \%$ & $20 \%$ & $58 \%$ \\
\hline & $25 \%$ & $67 \%$ & $8 \%$ & $0 \%$ & $0 \%$ & $83 \%$ \\
\hline & $19 \%$ & $64 \%$ & $6 \%$ & $0 \%$ & $0 \%$ & $85 \%$ \\
\hline & $35 \%$ & $55 \%$ & $10 \%$ & $0 \%$ & $0 \%$ & $85 \%$ \\
\hline
\end{tabular}

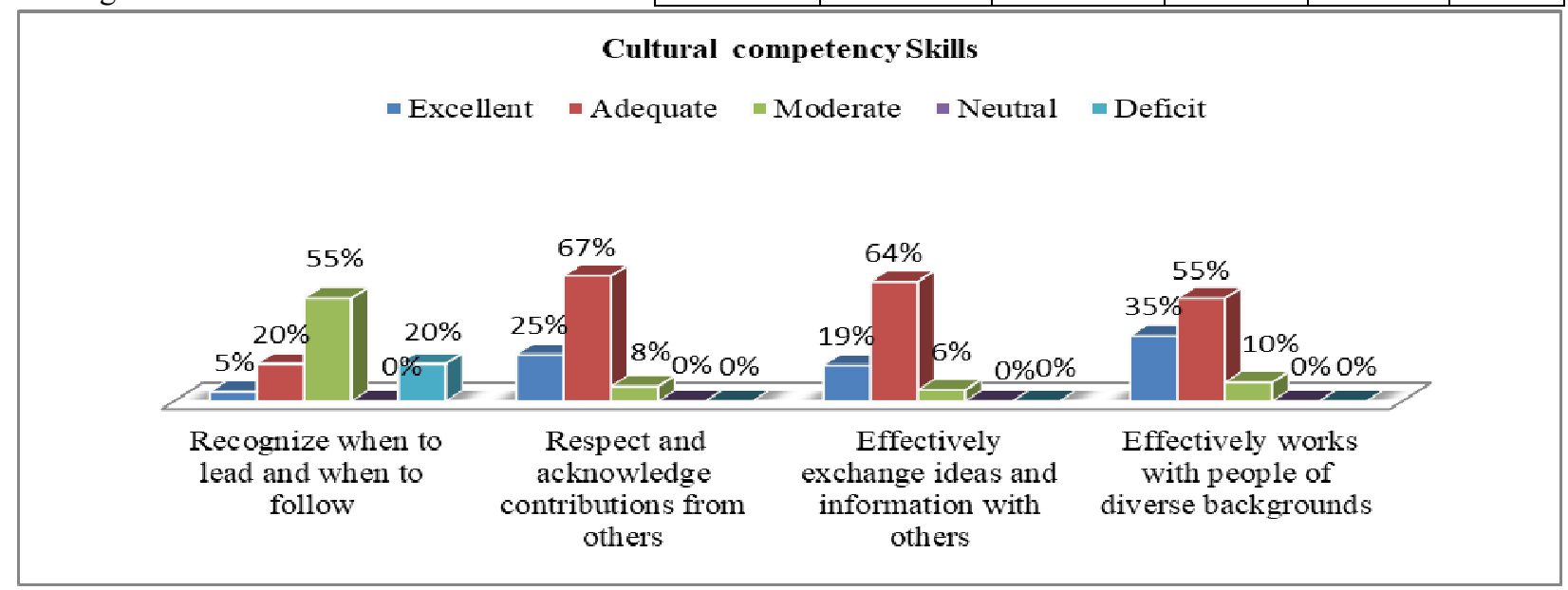

Inference: Overall the respondents are doing well in terms of indicators like Respect and acknowledge contributions from others", "Effectively exchange ideas and information with others", "Effectively works with people of diverse backgrounds" but they are slightly sort of expectation in terms of indicators like "Recognize when to lead and when to follow 


\section{Limitations}

The study was undertaken by administering the questionnaire to randomly selected students in the UAE and as such generalization of the finding is limited to that extent. The finding are viewed as possible improvement for greater success in collegiate education and should not be construed as a demotivation of any sort among students in the UAE.

\section{Conclusion}

In this paper, five areas of soft skills are explored in an effort to find out the Soft-skills gap among randomly surveyed secondary students in UAE. The five components are: communication skills, problem-solving and decision making skills, time management skills, teamwork and interpersonal skills, cultural competency skills. The findings are that while most students are rated well in many areas of soft skills, some improvement is possible in areas like "Listen effectively" and "Effective written communication" "Think outside the box", "Be Creative", "Take effective and appropriate decisions ", "Take initiative" Sense of urgency to complete tasks" and "Work well under pressure" "Work with multiple approaches", and "Consistently demonstrates cooperation to complete a task", Recognize when to lead and when to follow"

These scoring implications for each survey indicators are considered more pertinent for secondary school leaving students in their effort to succeed independently in a traditional collegiate environment. An individual respondent scoring below 60 percent suggests that the student is more likely to experience difficulty in coping within a traditional college setting. For such students, specialized strategies and skills-building programs may prove to be beneficial before pursuing a traditional college experience

As post-secondary education look forward to college readiness, the increasing attention soft skills receive in preparing students for postsecondary success need not be overemphasized. In an increasingly diverse and globalized outlook, balanced approach to education is required to ensure that all students graduate from school with both rigorous content knowledge coupled with the required soft skills. To achieve this, adequate efforts must be directed into closer alignment with postsecondary expectations. Factors that contribute to such gaps as identified by the survey results will be useful for institutions to integrate and align soft skills into curriculum towards better knowledgeable and skillful human capital. The concern about quantifying student achievement in certain areas of these skills needs special focus and adequate attempts should be aimed at to overcoming these concerns by ensuring that the stack holders approach these assessments with the proper contents.

The study in the short term lead to an understanding of soft skill deficit gap identified by the time they enter the corridors of university. In the medium term, students will be equipped with the necessary soft skills to bridge the identified gap in readiness for university education and learning. In the long term, students will be better equipped for industry in the UAE

\section{References}

Claxton, G., Costa, A., \& Kallick, B. (2016). Hard thinking about soft skills. Educational Leadership, 73(6), 6064.

Diakiw, J. (2016). Good for kids, good for us: Socio-emotional skill development in the early years. Our Schools Our Selves, 25(2), 39-46. Retrieved from https://diakiwsdigest.wordpress.com/2016/02/11/good-for-kidsgood-for-us/

Duckworth, A. (2016). Grit: The power of passion and perseverance. New York, NY: Simon \& Schuster.

Evans Allvin, R. (2016). The push up of 21 st century learning skills: The answer has always been in the early years. Young Children, 71(3), 48-51.

Jana, L. (2017). The toddler brain: Nurture the skills today that will shape your child's tomorrow. MA: Da Capo Lifelong Books.

Rao, M. (2012). Myths and truths about soft skills. T+D Talent Development, 66(5), 48-51.

Service, R. (2016). Finding happiness and balance in life. Taranaki Daily News. p.1634

Soffel, J. (2016). What are the 21st-century skills every student needs? Retrieved from https://www.weforum.org/agenda/2016/03/21st-century-skills-future-jobs-students/

Succi, C. (2015). Soft skills for the next generation: Toward a comparison between employers and graduate students' Perceptions. Sociologia Del Lavoro, (137), 244-256.

Tedesco, J., Opertti, R., \& Amadio, M. (2014). The curriculum debate: Why it is important today. Prospects, 44(4), 527-546.

Torrey, D. (2015). Education needs a purpose. Education Review. Retrieved from http://www.educationreview.co.nz/magazine/december-2015/education-needs-a-purpose/\#.WMIN-m-GOpp

Tulgan, B. (2016). Taking the Lead with soft skills. School Business Affairs.

Retrieved from https://www.schoolbusinessaffairs.org/books/asbofebruary2016/files/assets/basichtml/page44.html

Wats, M., \& Wats, R. (2009). Developing soft skills in students. The International Journal of Learning, 15(12), 
$1-10$.

Claxton,G(2006). Thinking at the edge: developing soft creativity. Cambridge Journal of Education 36(3):351362

Dourussen,H Lenz, $\mathrm{H}$ and Blavoukos, S(2005).'Assessing the reliability and validity of expert interviews'.Europian Union Politics 6(3):315-337

Edarabia (2010).UAE: Rise in number of students to boost demand for higher education'.(Ref: www.edarabia.co/11342)

NQA, Abu Dhabi (2013). The UAE Education System: overview of performance in education. Abu Dhabi: National Qualification Authority.

Ortloff, D.H., Shah, P.P. Lou, J \& Hamilton, E (2012). 'International education in secondary schools explored: a mixed- method examination of one Midwestern state in the USA'. Intercultural Education 23(2):161-180

The World Bank(2012).Knowledge Economy Index. Washington D.C: World Bank 